\title{
The Driselase-treated fraction of rice bran is a more effective dietary factor to improve hypertension, glucose and lipid metabolism in stroke-prone spontaneously hypertensive rats compared to ferulic acid
}

\author{
Ardiansyah $^{1 *}$, Hitoshi Shirakawa ${ }^{1}$, Takuya Koseki $^{2}$, Katsumi Hashizume ${ }^{2}$ and Michio Komai ${ }^{1}$ \\ ${ }^{1}$ Laboratory of Nutrition, Department of Science of Food Function and Health, Graduate School of Agricultural Science, Tohoku \\ University, Japan \\ ${ }^{2}$ National Research Institute of Brewing (NRIB), Hiroshima, Japan
}

(Received 5 April 2006 - Revised 18 July 2006 - Accepted 18 July 2006)

\begin{abstract}
The aim of this study is to investigate the effects of dietary supplementation with the Driselase-treated fraction (DF) of rice bran and ferulic acid (FA) on hypertension and glucose and lipid metabolism in stroke-prone spontaneously hypertensive rats (SHRSP). Male SHRSP at 4 weeks of age were divided into three groups, and for 8 weeks were fed (1) a control diet based on AIN-93M, (2) a DF of rice bran-supplemented diet at $60 \mathrm{~g} / \mathrm{kg}$ and (3) an FA-supplemented diet at $0.01 \mathrm{~g} / \mathrm{kg}$. Means and standard errors were calculated and the data were tested by one-way ANOVA followed by a least significance difference test. The results showed that both the DF and FA diets significantly improved hypertension as well as glucose tolerance, plasma nitric oxide (NOx), urinary 8-hydroxy-2'-deoxyguanosine and other parameters. In particular, compared to the FA diet, the DF diet produced a significant improvement in urinary NOx, hepatic triacylglycerol and several mRNA expressions of metabolic parameters involved in glucose and lipid metabolisms. The results of the metabolic syndrome-related parameters obtained from this study suggest that the DF diet is more effective than the FA diet.
\end{abstract}

Rice bran: Driselase fraction: Ferulic acid: Blood pressure: Glucose metabolism: Lipid profile

High blood pressure (BP), one manifestation of CVD, continues to be a major cause of morbidity and death. The control of high BP through diet has been a focus of public health strategies. A $5 \mathrm{mmHg}$ decrease in $\mathrm{BP}$ has been equated with a $16 \%$ decrease in CVD (FitzGerald et al. 2004). At present, considerable effort is being made to identify and exploit the bioactive components in foods which may contribute to reducing the risk of CVD.

It is recognized that multiple factors related to the metabolic state, such as changes in the glucose and lipid profiles and insulin resistance, complicate the management of high BP, particularly in diabetic conditions. Therefore, any food component having the ability to reduce high BP is a potential candidate for the prevention or treatment of CVD.

Rice bran, which is derived from the outer layer of the rice grain, is a by-product of the rice milling process. Rice bran is composed of the aleurone layer of the rice kernel and some part of the endosperm and germ. It is well known that the antioxidants in rice bran, namely tocopherol, tocotrienol and $\gamma$-oryzanol (a ferulate ester of triterpene alcohols), are isolated from the lipid-soluble extracts of the bran (Saunders, 1990) and have potent hypocholesterolaemic and antitumour activities (Sheetharamaiah \& Chadrasekhara, 1988; Qureshi et al. 2000). It has previously been reported that rice has antioxidative ability as described later. Aqueous ethanol extracts of rice bran exhibited antioxidative properties (Choi et al. 1996), dietary pigmented rice protected against lipid peroxidation in rat kidneys (Toyokuni et al. 2002) and pigmented rice suppressed reactive oxygen species in an in vitro assay (Hu et al. 2003). A recent report showed that the outer layer fraction of black rice inhibits atherosclerotic plaque formation, lowers aortic 8-hydroxy-2'-deoxyguanosine (8-OHdG) and decreases malondialdehyde levels induced by hypercholesterolaemia in the serum and aorta of rabbits (Ling et al. 2002). Our previous study demonstrated that the Driselase-treated fraction (DF) - the filtrate of rice bran treated with plant cell wall-degrading enzyme mixtures - has a beneficial effect on lowering BP and improving lipid profiles, and these effects were observed in both the ethanol and lipid-soluble fractions of rice bran (Ardiansyah et al. 2006).

4-Hydroxy-3-methoxycinnamic acid (ferulic acid, FA) is the most common phenolic compound in cereal cell walls (Smith \& Hartley, 1983; Abdel-Aal et al. 2001). It is most abundant in the aleurone, pericarp and embryo cell walls and occurs in

\footnotetext{
Abbreviations: ACE, angiotensin-1 converting enzyme; BP, blood pressure; BUN, blood urea nitrogen; C diet, control diet; DF, Driselase-treated fraction; FA, ferulic acid; FXR, farnesoid X receptor; G6Pase, glucose-6-phosphatase; LDL-C, LDL-cholesterol; MRP-2, multi-drug resistance protein-2; NOx, nitric oxide; 8-OHdG, 8hydroxy-2'-deoxyguanosine; PEPCK, phosphenolpyruvate carboxykinase; SHRSP, stroke-prone spontaneously hypertensive rats; SHP, small heterodimer partner; TG, triacylglycerol; TC, total cholesterol.

* Corresponding author: Mr Ardiansyah, 1-1 Tsutsumidori-Amamiyamachi, Aoba-ku, Sendai 981-8555, Japan, fax +81 22 717 8813, email ardy@ biochem.tohoku.ac.jp
} 
only trace amounts in the endosperm (Smith \& Hartley, 1983). FA has antioxidant properties that make it an important antiageing supplement, and these properties also contribute to the other potential uses of FA. Various studies have indicated that purified FA acts as a photo-protective agent; it has antioxidative effects, lowers blood glucose levels in streptozotocin-induced diabetic rats and lowers BP in spontaneously hypertensive rats (Conessa et al. 1999; Saija et al. 1999; Suzuki et al. 2002; Balasubashini et al. 2003). Analysis by our research group has shown that the FA content of DF is $0.19 \mathrm{mg} / 100 \mathrm{~g}$. Another study reported that rice bran contains approximately $0.1 \%$ FA (Yan et al. 2001).

At present, considerable effort is being focused on the search for similar types of bioactive components in foods which may contribute to reducing the risk of CVD. Various edible plants, including vegetables, fruits and cereals have been considered as having properties that contribute to the prevention of CVD. The antioxidative constituents of these foods are of considerable importance because they possess a scavenging property. The aim of the present study was to assess whether compared to FA as a purified component of plant cell wall, DF is effective in improving hypertension, and glucose and lipid metabolism in stroke-prone spontaneously hypertensive rats (SHRSP) that have a heredity predisposition to hypertension.

\section{Material and methods}

\section{Preparation of rice bran fraction}

We used the DF of rice bran in the present study as a test substance. The preparation of the DF was based on our previous study (Ardiansyah et al. 2006). The outer layer of rice $(500 \mathrm{~g}$ ) was agitated in 1.0 litre $70 \%$ ethanol for $2 \mathrm{~h}$ and filtered, yielding two fractions (the solid and suspension fractions). The DF was derived from the solid fraction. Driselase is a commercial plant cell wall-degrading enzyme mixture containing cellulases, xylanases and laminarinases, but not esterases. The solid fraction was dried at room temperature and then resuspended in $500 \mathrm{ml}$ acetate buffer $(10 \mathrm{mmol} / \mathrm{l}$, $\mathrm{pH} 5 \cdot 0)$, containing Driselase $(0.2 \mathrm{mg} / \mathrm{l}$; Sigma Chemical Co., St Louis, MO, USA). After Driselase treatment overnight at $37^{\circ} \mathrm{C}$, the suspension was filtered and finally lyophilized.

\section{Animal experiments}

Four-week-old male rats of the inbred SHRSP/Izumo strain were used in the present study. They were housed in individual stainless steel cages in a room maintained at $23 \pm 2^{\circ} \mathrm{C}$ with $50 \pm 10 \%$ humidity and a $12 \mathrm{~h}$ light-dark cycle. The rats were given free access to a fresh diet and drinking water for 8 weeks. The composition of the experimental diets shown in Table 1 is based on an AIN-93M diet supplemented with either $60 \mathrm{~g} \mathrm{DF} / \mathrm{kg}$ or $0.01 \mathrm{~g} \mathrm{FA} / \mathrm{kg}$ as test substances. The basal diet (C) was supplemented with the DF based on our previous study (Ardiansyah et al. 2006) and FA as described by Suzuki et al. (2002). Food intake was recorded every day. Body weight and BP were measured once a week. The experimental plan of the present study was approved by the Animal Research-Animal Care Committee of the Graduate School of Agricultural Science, Tohoku
Table 1. Composition of experimental diets based on the AIN-93 diet (Reeves et al. 1993)*

\begin{tabular}{lccc}
\hline Ingredient (g/kg) & C & DF & FA \\
\hline tert-Butylhydroquinone & 0.008 & 0.008 & 0.008 \\
L-Cystine & 1.8 & 1.8 & 1.8 \\
Choline bitartrate & $2 \cdot 5$ & 2.5 & 2.5 \\
Vitamin mixture & 10 & 10 & 10 \\
Mineral mixture & 35 & 35 & 35 \\
Soyabean oil & 40 & 40 & 40 \\
Cellulose & 50 & 50 & 50 \\
Sucrose & 100 & 100 & 100 \\
Casein & 140 & 140 & 140 \\
Cornstarch & 620 & 560 & 620 \\
Test substance & - & 60 & 0.01 \\
\hline
\end{tabular}

C, control diet; DF, Driselase-treated fraction diet; FA, ferulic acid diet. * tert-Butylhydroquinone, L-cystine, choline bitartrate and soyabean oil were purchased from the Wako Pure Chemical Co. (Osaka, Japan) and vitamin and mineral mixtures, cellulose, sucrose and casein were obtained from the Oriental Yeast Co. (Tokyo, Japan). Driselase from Basidiomycetes sp. was purchased from the Sigma Chemical Co. (St Louis, MO, USA).

University. The entire experiment closely followed the guidelines issued by the committee which strictly follows government legislation in Japan.

\section{Oral glucose tolerance test}

Three days prior to being killed, all animals were used for an oral glucose tolerance test. The animals were fasted for $16 \mathrm{~h}$. Blood for glucose measurement was collected from the tail vein 30, 60 and $120 \mathrm{~min}$ before and after being fed glucose $(1.8 \mathrm{~g} / \mathrm{kg}$ body weight $)$ via a gastric tube. Plasma glucose levels were measured by enzymatic colorimetric methods (Wako Pure Chemical Co., Osaka, Japan). The analysis of the incremental area under the curve of the plasma glucose response was calculated based on the method of Wolever \& Jenkins (1986).

\section{Blood pressure measurement}

BP was measured once a week using the tail cuff method with a BP meter without warming (MK-2000; Muromachi Kikai, Tokyo, Japan). At least seven repeated BP measurements were taken for each rat. Averages of four consistent readings of the systolic BP were taken to represent the individual systolic BP.

\section{Sample collection}

The rats were transferred to metabolic cages for $24 \mathrm{~h}$ for the collection of urine $5 \mathrm{~d}$ prior to being killed. Urine was filtered and stored at $-20^{\circ} \mathrm{C}$ until required for later analysis. Rats were killed after $16 \mathrm{~h}$ fasting, under light diethyl ether anaesthesia. Blood samples were centrifuged at $1870 \mathrm{~g}$ for $15 \mathrm{~min}$ at $4^{\circ} \mathrm{C}$ in a centrifuge (CF7D2; Hitachi Co. Ltd, Tokyo, Japan). The livers were promptly excised and washed with ice-cold isotonic saline. Both plasma and liver tissue samples were stored at $-70^{\circ} \mathrm{C}$ until required for later analysis. 
Plasma, liver and urine parameters

Plasma levels of blood urea nitrogen (BUN), albumin, glucose, total cholesterol (TC), triacylglycerol (TG) and HDLcholesterol levels were determined by enzymatic colorimetric methods (Wako Pure Chemical Co.). The concentration of LDL-cholesterol (LDL-C) was calculated by Friedewald's formula (Friedewald et al. 1972). Liver total lipids were determined according to Folch et al. (1957). Liver TC and TG concentrations were determined using the same kit as for plasma TC and TG, following extraction of liver samples with methanol-chloroform $(2: 1, \mathrm{v} / \mathrm{v})$. Plasma and urinary levels of creatinine were measured by enzymatic colorimetric methods (Wako Pure Chemical Co.), and the results were used to determine the creatinine clearance parameter. Plasma insulin levels were measured in vitro by a RIA technique using a commercial kit from ShionoRIA Insulin (Shionogi Co., Osaka, Japan).

\section{Assay of angiotensin-1 converting enzyme activity}

Angiotensin-1 converting enzyme (ACE) activity in the plasma was determined according to the method of Cushman \& Cheung (1971) with slight modifications. Hippuryl-L-histidyl-L-leucine $(150 \mu \mathrm{l}, 5 \mathrm{mmol} / \mathrm{l})$ in borate buffer $(100 \mathrm{mmol} / \mathrm{l}$ borate and $100 \mathrm{mmol} / \mathrm{l} \mathrm{NaCl}, \mathrm{pH} \mathrm{8.3)}$ was preincubated at $37^{\circ} \mathrm{C}$ for $10 \mathrm{~min} ; 60 \mu \mathrm{l}$ of the sample were added and the mixture was incubated at $37^{\circ} \mathrm{C}$ for $30 \mathrm{~min}$. The content of hippuric acids liberated from hippuryl-L-histidyl-L-leucine by the enzymatic reaction of ACE was spectrophotometrically measured at $228 \mathrm{~nm}$ after ethyl acetate extraction. One unit of ACE activity was defined as the amount of enzyme that cleaved 1 mol substrate per min.

\section{Assay of nitric oxide concentrations}

The nitrate/nitrite (nitric oxide, NOx) levels in the plasma and urine were quantified by the Griess method $\left[\mathrm{NO}_{2} / \mathrm{NO}_{3}\right.$ Assay kit-C II (Colorimetric); Dojindo, Kumamoto, Japan]. The NOx levels were assayed after ultrafiltration using centrifugal filter devices (Amicon 100 UFC 3 LGC 00; Millipore, Bedford, MA, USA). Samples were read at $540 \mathrm{~nm}$ in a ninety-sixwell plate using a Spectra Microplate Auto reader (Bio-Rad Model 680; Hercules, CA, USA).
Analysis of 8-hydroxy-2'-deoxyguanosine

Levels of urinary $8-\mathrm{OHdG}$ were determined by an indirect competitive ELISA (New 8-OHdG Check; Institute for the Control of Aging, Shizuoka, Japan). The procedure for sample pretreatment and that for performing the assay were carried out according to the instruction manual. The absorbance was measured at $450 \mathrm{~nm}$ using a Spectra Microplate Auto reader (Bio-Rad Model 680). The concentration of 8$\mathrm{OHdG}$ in the urine samples was interpolated from a standard curve drawn with the assistance of logarithmic transformation. The results were expressed as ng/mg creatinine.

\section{$R N A$ preparation and quantitative real-time-PCR}

Total RNA was isolated from the liver with a guanidine isothiocyanate-based reagent, Isogen (Nippon Gene Co., Toyama, Japan) according to the instruction manual. The measurement of the wavelength ratio at 260 and $280 \mathrm{~nm}$ and agarose gel electrophoresis were performed to facilitate the quantitative and qualitative analysis of the isolated RNA. Total RNA $(5 \mu \mathrm{g})$ was used as a template to synthesize the cDNA. The RNA was denaturated with oligo-dT/random primers; $10 \mathrm{mmol} / 1 \mathrm{dNTP}$ (Amersham Biosciences, Piscataway, NJ, USA) and distilled water were added at $65^{\circ} \mathrm{C}$ for $5 \mathrm{~min}$. The RNA was then incubated in $50 \mathrm{mmol} / \mathrm{l}$ Tris- $\mathrm{HCl}$ buffer ( $\mathrm{pH} 8 \cdot 3$ ); $0 \cdot 1$ M-dithiothreitol containing 50 units of SuperScript III RT (Invitrogen, Carlsbad, CA, USA) and 20 units of RNaseOUT RNase inhibitor (Invitrogen) in $20 \mu \mathrm{l}$ at $25^{\circ} \mathrm{C}$ for $5 \mathrm{~min}, 50^{\circ} \mathrm{C}$ for $60 \mathrm{~min}$ and $70^{\circ} \mathrm{C}$ for $15 \mathrm{~min}$. Aliquots of the cDNA were used as a template for the following quantitative real-time-PCR using an Applied Biosystems Sequence Detection System 7000 (Foster City, CA, USA) according to the manufacturer's instructions. The relative expression levels of gene expression were normalized by the amount of eukaryotic elongation factor- $1 \alpha 1$ mRNA. The genes listed in Table 2 were amplified by cDNA specific primers in an Applied Biosystems Syber Green Master Mix PCR solution.

\section{Statistical analysis}

Values are presented as means and their standard errors. To evaluate the differences among the groups studied, one-way ANOVA followed by the Fisher post hoc test was used. The SAS software StatView-J version 5.0 (SAS Institute Inc.,

Table 2. Sequences of primers for PCR amplifications

\begin{tabular}{lll}
\hline Gene & Forward primer & Reverse primer \\
\hline EF-1 & GATGGCCCCAAATTCTTGAAG & GGACCATGTCAACAATTGCAG \\
FXR & AGCGGCATCTCCGATGAGTA & TCTGGAGAGAGGATGACAATTGC \\
HMGCR & AATTGTGTGTGGCACTGTGATG & GATCTGTTGTGAACCATGTGACTTCT \\
SHP & ACGCATACCTGAAGGCACTATC & CAGGGCTCCAGGACTTCACA \\
MRP2 & AACCCAAGCTGAGGCCAGAC & GCTGCACTTCCGGAGACAG \\
LFABP & AGTACCAAGTGCAGAGCCAAGAG & GCAGACCCATCGCCTTCA \\
VLACS & ACTCTTTCAGCACATCTCGGAGTA & CCGGTCATCTCAATGGTATCTTGTA \\
PEPCK & GAGGACATTGCCTGGATGAATTT & TGGGTTGATGGCCCTTAAGT \\
G6Pase & TTGTGCATTTGCTAGGAAGAGAAG & ATCTAAAGACCCAGGCATAACTGAAG \\
\hline
\end{tabular}

EF-1, eukaryotic elongation factor-1 $\alpha 1$; FXR, farnesoid X receptor; G6Pase, glucose-6-phosphatase; HMGCR, 3-hydroxy-3-methylglutaryl-CoA reductase; LFABP, liver fatty acid-binding protein; MRP-2, multi-drug resistance protein-2; PEPCK, phosphenolpyruvate carboxykinase; SHP, small heterodimer partner; VLACS, very long-chain acyl-CoA synthetase. 
Cary, NC, USA) was used to analyse all data. Probability values of $P<0.05$ and $P<0.01$ were considered as significant.

\section{Results}

Food intake, body weight and food efficiency ratio

Experimental diets did not affect the food intake, final body weight and food efficiency ratio (data not shown). The intake of DF and FA diet groups are 1.45 (SE 0.03) g/d and 0.25 (SE 0.00) $\mathrm{mg} / \mathrm{d}$, respectively.

Blood pressure, angiotensin-1 converting enzyme activity and kidney function

An increase in BP was observed in all the diet groups from 6 weeks of age until the end of the experimental period (Fig. 1). On the other hand, the BP of the DF diet group showed a significant reduction beginning at 6 weeks of age until the end of the experimental period; a similar reduction was seen in the FA group beginning at 7 weeks of age. At 10 weeks, the FA group showed a considerable reduction in $\mathrm{BP}$ compared to the DF and control (C) groups. At the end of the experimental period, the BP was 245.29 (SE 5.99), 223.83 (SE 5.17) and 216.17 (SE 8.50) $\mathrm{mm} \mathrm{Hg}$ for the C, DF and FA diet groups, respectively. With respect to the analysis of plasma ACE activity, the $\mathrm{C}$ diet group had the highest value at the end of the study (Fig. 2), whereas the activities of the DF and FA diet groups were both significantly lower than that of the $\mathrm{C}$ diet group $(P<0.05)$. The DF diet group showed a significant reduction in the plasma BUN (2.98 (SE 0.21) mmol/l), BUN: creatinine ratio $(0.05$ (SE 0.004)) and albumin levels $(0.58$ $($ SE $0.04 \mu \mathrm{mol} / 1))(P<0.05)$, while the FA diet group exhibited a significant reduction only in albumin $(0.59$ (SE 0.02$) \mu \mathrm{mol} / \mathrm{l})$ level compared to the $\mathrm{C}$ diet group $(P<0.05)$. The value of BUN, BUN:creatinine ratio and albumin levels for the $\mathrm{C}$ group was 3.82 (SE 0.18) mmol/l, 0.06 (SE 0.002) and 0.66 (SE 0.02) $\mu \mathrm{mol} / \mathrm{l}$, respectively.

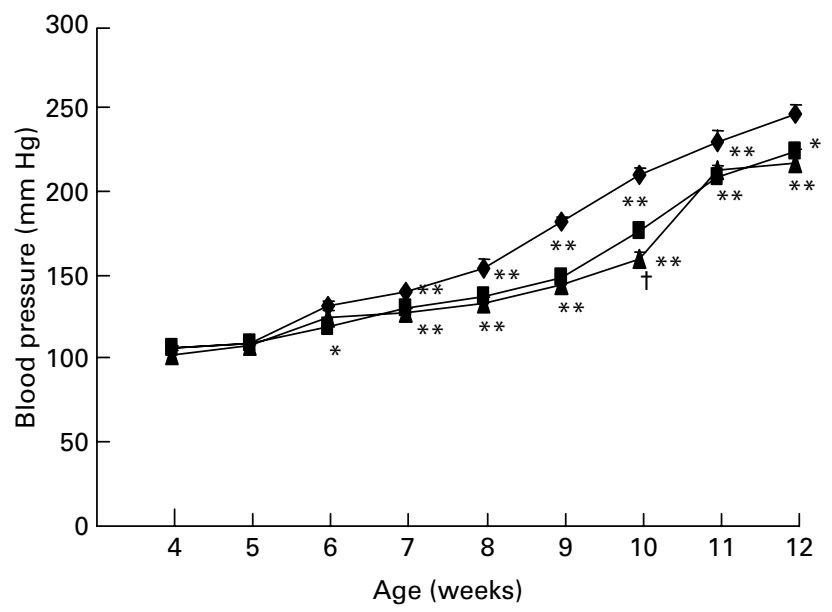

Fig. 1. Effect of experimental diets ( $\bullet$, control diet; $\mathbf{\square}$, Driselase-treated fraction diet (DF); $\boldsymbol{\Lambda}$, ferulic acid diet) on systolic blood pressure in rats. For details of procedures, see pp. 68-69. Values are means with their standard errors depicted by vertical bars (six rats per group). Mean values were significantly different from those of the control group: ${ }^{\star} P<0.05$; ${ }^{\star \star} P<0.01$. Mean values were significantly different from those of the DF group: $\dagger P<0.05$.

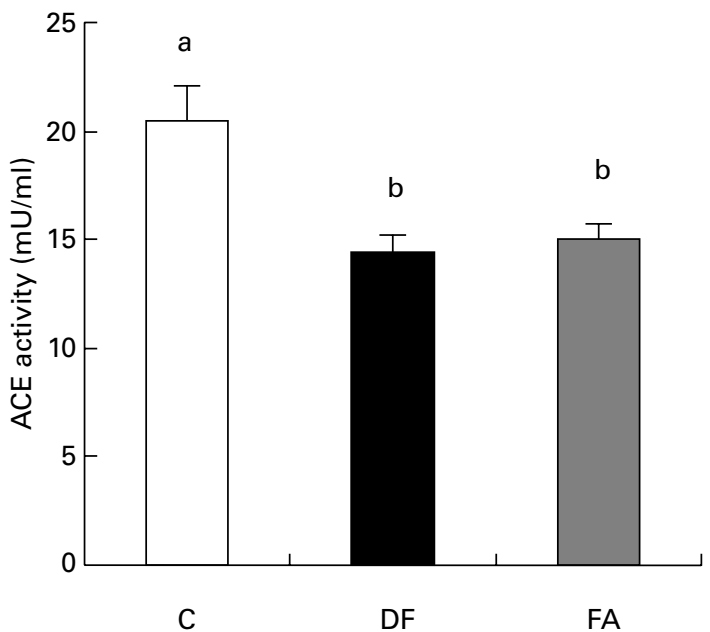

Fig. 2. Effect of experimental diets (C, control diet; DF, Driselase-treated fraction diet; FA, ferulic acid diet) on plasma angiotensin-1 converting enzyme (ACE) activity in rats. For details of procedures, see pp. 68-69. Values are means with their standard errors depicted by vertical bars (six rats per group). ${ }^{a, b}$ Mean values with unlike superscript letters were significantly different $(P<0.05)$.

\section{Nitric oxide and 8-hydroxy-2'-deoxyguanosine levels}

The plasma and urinary NOx levels of rats fed the experimental diets are shown in Fig. 3. The plasma NOx levels of both the DF and FA diet groups were significantly lower than that of the $\mathrm{C}$ diet group; however, the urinary NOx excretion was reduced only in the DF diet group $(P<0 \cdot 05)$. The effect of the experimental diets on urinary $8-\mathrm{OHdG}$ levels is shown in Fig. 4. Both test diets significantly lowered the urinary 8 OHdG levels when compared with the control diet $(P<0 \cdot 05)$.

\section{Plasma and liver lipid levels}

Table 3 shows the plasma and liver lipid levels recorded in the present experiment. The DF and FA diet groups showed significantly lower plasma TC, LDL-C and TG levels than the $\mathrm{C}$ diet group $(P<0 \cdot 05)$. The average HDL-cholestrol:LDL-C ratio in the DF diet group was higher than that in the other diet groups, although the difference was not significant. Total lipid content was significantly increased in the FA diet group when compared to that in the DF diet group $(P<0.05)$. Moreover, the DF diet group showed a significant decrease in the level of liver TG compared to the $\mathrm{C}$ and FA diet groups $(P<0 \cdot 05)$.

\section{Plasma glucose and insulin levels}

At the end of the experiment, the plasma glucose level in the DF diet group was lower than that in the FA diet group and was significantly lower than that in the $\mathrm{C}$ diet group $(P<0.05)$ (Table 4); however, there was no significant difference between the FA and C diet groups. However, both the DF and FA diet groups had significantly lower glucose levels as assessed by the incremental area under the curve of glucose in the oral glucose tolerance test $(P<0.05)$ (Fig. 5). The plasma insulin levels showed a significant increase in the FA diet group compared to the DF and $\mathrm{C}$ diet groups $(P<0 \cdot 05)$. 

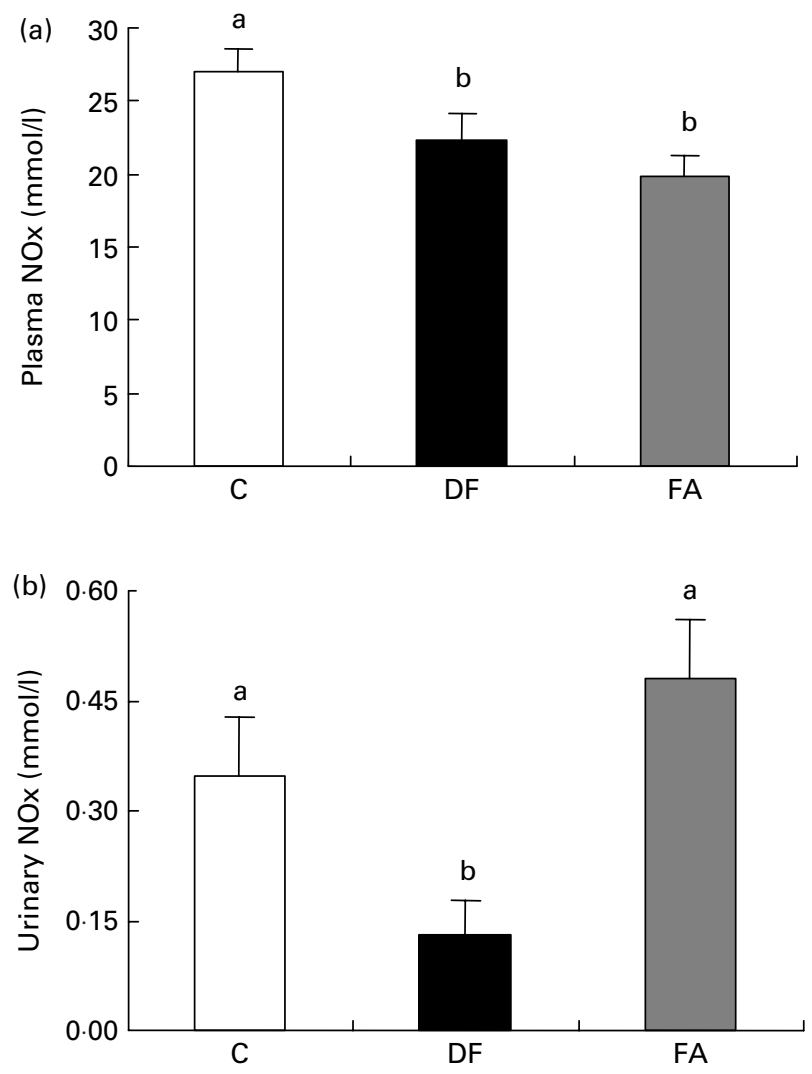

Fig. 3. Effect of experimental diets (C, control diet; DF, Driselase-treated fraction diet; FA, ferulic acid diet) on plasma (A) and urinary (B) nitric oxide (NOx) levels in rats. For details of procedures, see pp. 68-69. Values are means with their standard errors depicted by vertical bars (six rats per group). ${ }^{a, b}$ Mean values with unlike superscript letters were significantly different $(P<0.05)$.

\section{mRNA expression levels}

The mRNA expression levels of glucose and lipid metabolic genes are shown in Figs. 6 and 7. We found that the DF diet group had significantly repressed mRNA levels of liver fatty acid-binding protein and very long-chain acyl-CoA synthetase and, compared to the $\mathrm{C}$ diet group, tended to have lower levels of farnesoid X receptor (FXR), small heterodimer partner (SHP) and multi-drug resistance protein-2 (MRP2) (Fig. 7). Interestingly, the DF group showed a significant down-regulation in the mRNA levels of FXR, SHP and MRP2 compared to the FA diet group $(P<0.05$; Fig. 7). There was no change in the expression of glucose-6-phosphatase (G6Pase) among all the experimental diet groups. Compared to the $\mathrm{C}$ diet group, the FA diet group exhibited significantly down- and up-regulated expression levels of the very long-chain acyl-CoA synthetase and 3-hydroxy-3methylglutaryl-CoA reductase genes, respectively $(P<0 \cdot 05)$. However, no significant differences in the mRNA levels of FXR, SHP and MRP2, which are involved in lipid metabolism, were observed. When compared to the $\mathrm{C}$ diet group, the FA diet group also exhibited a significant up-regulation in the mRNA levels of phosphenolpyruvate carboxykinase (PEPCK) - a compound involved in glucose metabolism $(P<0 \cdot 05$; Fig. 6).

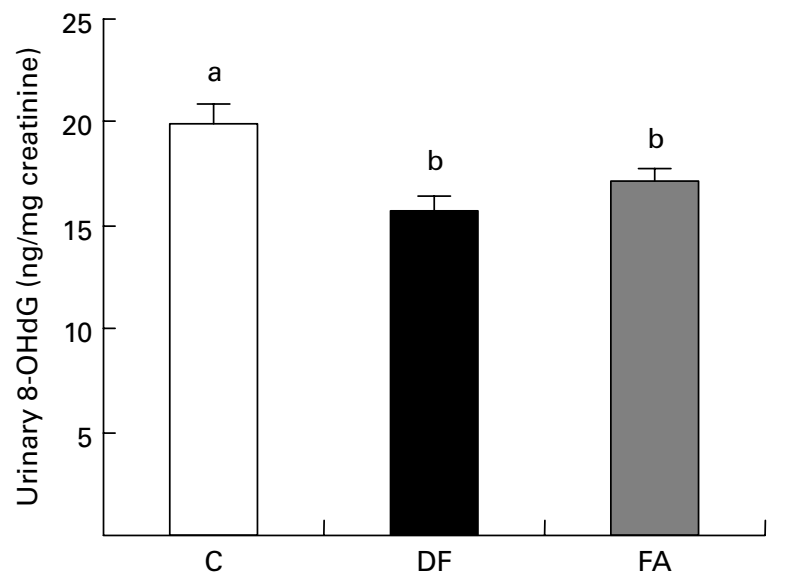

Fig. 4. Effect of experimental diets (C, control diet; DF, Driselase-treated fraction diet; FA, ferulic acid diet) on urinary 8-hydroxy-2'-deoxyguanosine (8-OHdG) levels in rats. For details of procedures, see pp. 68-69. Values are means with their standard errors depicted by vertical bars (six rats per group). ${ }^{\mathrm{a}, \mathrm{b}}$ Mean values with unlike superscript letters were significantly different $(P<0.05)$.

\section{Discussion}

We used SHRSP as an animal model of hypertension-related disorders similar to human essential hypertension (Yamori et al. 1979), hyperlipidaemia (Aitman et al. 1997), multisystem end-organ damage with prominent involvement of the kidney (proteinuria) (Okamoto et al. 1974), insulin resistance syndrome (Collison et al. 2000) and higher oxidative stress in the brain (Lee et al. 2004). However, rats are useful for some studies but they differ from man. Rats lacked cholesteryl ester transfer protein which renders their response to diet rather atypical (Groener et al. 1989).

The DF diet significantly reduced the BP from the second week of the feeding period to the end of the experiment. In a previous study, we have shown the possibility that the FA content of the DF from rice bran contributes to a reduction in BP (Ardiansyah et al. 2006). The results obtained in the present study suggest that the BP-lowering capacity of the DF diet is due to its FA content. Another study has reported that when free FA $(50 \mathrm{mg} / \mathrm{kg}$ body weight $)$ was orally administered to the spontaneously hypertensive rats, the BP was lowest after $1 \mathrm{~h}$, although the values returned to basal levels after $6 \mathrm{~h}$ (Suzuki et al. 2002). In addition, when the spontaneously hypertensive rats were administered FA at a rate of 10 or $50 \mathrm{mg} / \mathrm{kg}$ body weight per $\mathrm{d}$ in a test diet for 6 weeks, BP was reduced significantly when compared to the $\mathrm{BP}$ of the spontaneously hypertensive rats that were administered only a control diet (Suzuki et al. 2002).

ACE inhibitors reduce $\mathrm{BP}$ via the renin-angiotensin system; it was worthwhile examining the effect of the DF and FA diets on plasma ACE activity. In recent years, many studies have isolated and reported on the ACE inhibitory peptides from food protein sources, such as soyabean ( $\mathrm{Wu} \&$ Ding, 2001), wakame (Undaria pinnatifida; Sato et al. 2002), spinach Rubisco (Yang et al. 2003), Indonesian saltdried fish (Astawan et al. 1995) and soyabean protein hydrolysate (Yang et al. 2004). However, a few reports have demonstrated the presence of non-peptidyl ACE inhibitors, contained in foods such as ashitaba (Angelica keiskei; Shimizu 
Table 3. Effect of experimental diets on plasma total cholesterol, HDL-cholesterol (HDL-C), LDLcholesterol (LDL-C), HDL-C:LDL-C ratio, triacylglycerol, and liver total lipid, total cholesterol and triacylglycerol*

(Mean values with their standard errors for six rats per group)

\begin{tabular}{|c|c|c|c|c|c|c|}
\hline \multirow[b]{2}{*}{ Biochemical parameter } & \multicolumn{2}{|c|}{ C } & \multicolumn{2}{|c|}{ DF } & \multicolumn{2}{|c|}{ FA } \\
\hline & Mean & SEM & Mean & SEM & Mean & SEM \\
\hline \multicolumn{7}{|l|}{ Plasma } \\
\hline Total cholesterol $(\mathrm{mmol} / \mathrm{l})$ & $1.93^{\mathrm{a}}$ & 0.03 & $1.79^{\mathrm{b}}$ & 0.03 & $1.84^{\mathrm{b}}$ & 0.03 \\
\hline $\mathrm{HDL}-\mathrm{C}(\mathrm{mmol} / \mathrm{l})$ & 0.82 & $0 \cdot 10$ & 0.98 & 0.06 & 0.95 & 0.03 \\
\hline LDL-C (mmol/l) & $0.94^{a}$ & 0.09 & $0.67^{\mathrm{b}}$ & 0.06 & $0.74^{b}$ & 0.05 \\
\hline HDL-C:LDL-C ratio & 0.96 & 0.19 & 1.54 & 0.28 & 1.31 & 0.11 \\
\hline Triacylglycerol $(\mathrm{mmol} / \mathrm{l})$ & $0.86^{a}$ & 0.05 & $0.70^{\mathrm{b}}$ & 0.05 & $0.70^{\mathrm{b}}$ & 0.06 \\
\hline \multicolumn{7}{|l|}{ Liver } \\
\hline Total lipid (mg/g liver) & $91 \cdot 55^{\mathrm{ab}}$ & 3.50 & $81 \cdot 91^{\mathrm{a}}$ & 2.97 & $105 \cdot 16^{\mathrm{b}}$ & 9.38 \\
\hline Total cholesterol (mg/g liver) & 63.56 & 1.27 & $65 \cdot 84$ & 0.54 & 66.77 & 2.06 \\
\hline Triacylglycerol (mg/g liver) & $36 \cdot 72^{\mathrm{a}}$ & 1.64 & $31 \cdot 32^{b}$ & 0.69 & $33.41^{\mathrm{a}}$ & 2.53 \\
\hline
\end{tabular}

C, control diet; DF, Driselase-treated fraction diet; FA, ferulic acid diet.

${ }^{a, b}$ Mean values within a row with unlike superscript letters were significantly different $(P<0.05)$.

${ }^{*}$ For details of procedures, see pp. 68-69.

Table 4. Effect of experimental diets on plasma glucose, insulin and glucose:insulin ratio* (Mean values with their standard errors for six rats per group)

\begin{tabular}{|c|c|c|c|c|c|c|}
\hline \multirow[b]{2}{*}{ Biochemical parameter } & \multicolumn{2}{|c|}{ C } & \multicolumn{2}{|c|}{ DF } & \multicolumn{2}{|c|}{ FA } \\
\hline & Mean & SEM & Mean & SEM & Mean & SEM \\
\hline Glucose (mmol/l) & $8.73^{a}$ & 0.24 & $7.97^{b}$ & 0.16 & $8 \cdot 37^{\mathrm{ab}}$ & 0.29 \\
\hline Insulin (pmol/l) & $204 \cdot 72^{a}$ & $35 \cdot 34$ & $190 \cdot 09^{a}$ & 28.81 & $295 \cdot 83^{b}$ & 34.32 \\
\hline
\end{tabular}

C, control diet; DF, Driselase-treated fraction diet; FA, ferulic acid diet.

a,b Mean values within a row with unlike superscript letters were significantly different $(P<0.05)$.

${ }^{*}$ For details of procedures, see pp. 68-69.

et al. 1999) and garlic (Sharifi et al. 2003). In vitro analysis performed in our previous study showed that the antihypertensive effect of rice bran was due to ACE inhibitory activity in the plasma (Ardiansyah et al. 2006). According to the theory of the renin-angiotensin system, the activity of ACE should be lowered after the administration of an ACE inhibitor.

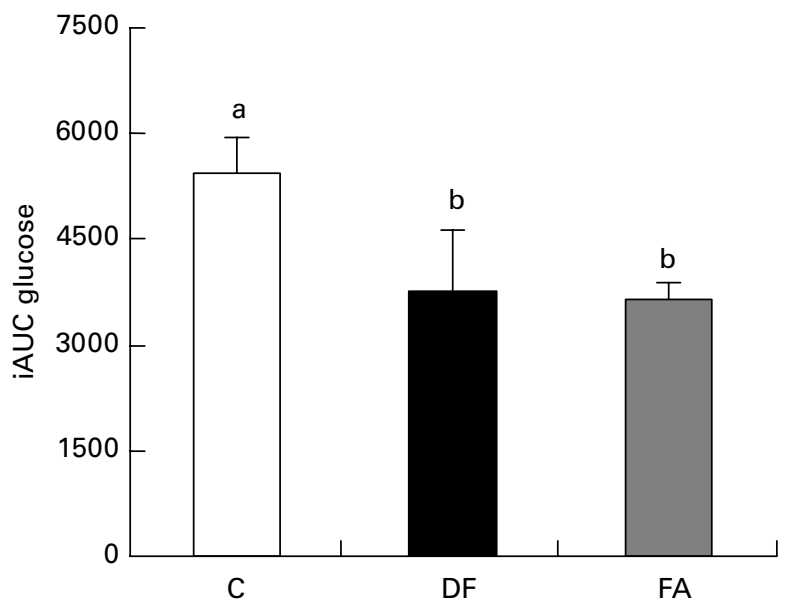

Fig. 5. Effect of experimental diets on the incremental area under the curve (iAUC) glucose in rats. For details of procedures, see pp. 68-69. Values are means with their standard errors depicted by vertical bars (six rats per group). ${ }^{a, b}$ Mean values with unlike superscript letters were significantly different $(P<0.05)$.
Therefore, the present data indicate that the antihypertensive effect of the DF and FA diets is due to the inhibition of ACE activity in the plasma. This is the first report to show that supplementary feeding of the DF and FA has antihypertensive effects through the inhibition of ACE activity in the plasma. The present finding suggests that the ACE inhibitory substances in both diets have a potent effect in reducing BP,

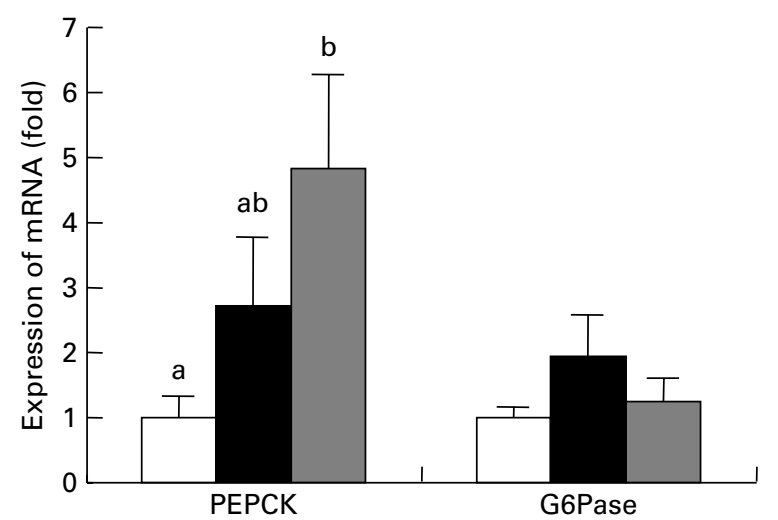

Fig. 6. Effect of experimental diets ( $\square$, control diet; $\mathbf{\square}$, Driselase-treated fraction diet (DF); $\square$, ferulic acid diet) on the mRNA levels of the glucose metabolic genes in rats. For details of procedures, see pp. 68-69. Values are means with their standard errors depicted by vertical bars (six rats per group). ${ }^{a, b}$ Mean values with unlike superscript letters were significantly different $(P<0.05)$. G6Pase, glucose-6-phosphatase; PEPCK, phosphenolpyruvate carboxykinase. 


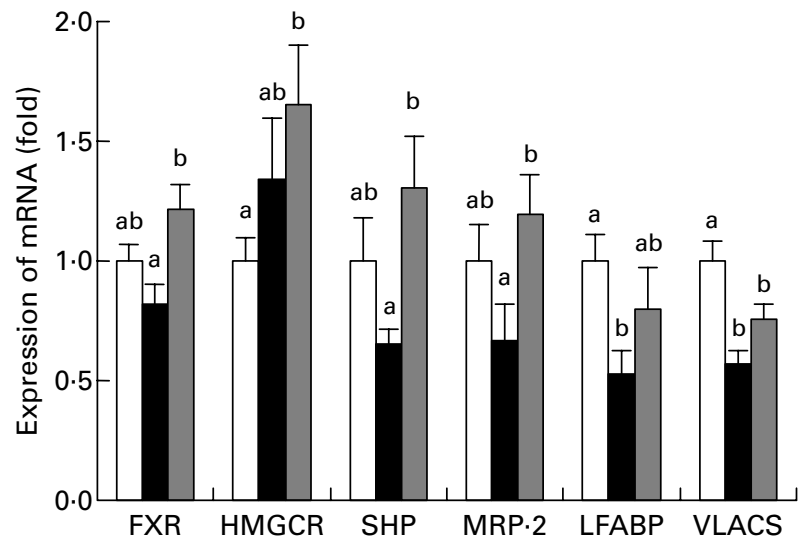

Fig. 7. Effect of experimental diets ( $\square$, control diet; $\square$, Driselase-treated fraction diet (DF); $\square$, ferulic acid diet) on the mRNA levels of lipid metabolic genes in rats. For details of procedures, see pp. 68-69. Values are means with their standard errors depicted by vertical bars (six rats per group). ${ }^{a, b}$ Mean values with unlike superscript letters were significantly different $(P<0.05)$. FXR, farnesoid X receptor; HMGCR, 3-hydroxy-3-methylglutarylCoA reductase; LFABP, liver fatty acid-binding protein; MRP-2, multi-drug resistance protein-2; SHP, small heterodimer partner; VLACS, very longchain acyl-CoA synthetase.

and this finding coincides with the results obtained with the non-peptidyl ACE inhibitory substance found in garlic (Sharifi et al. 2003). ACE inhibitors may mediate their antihypertensive effects via different mechanisms, and further studies need to be conducted on the mechanism of the DF and FA actions on related tissues. Hypertension is one of the leading causes of kidney diseases, which are also commonly called end-stage renal diseases. Therefore, it is of interest to evaluate whether antihypertensive treatment could improve kidney function. The DF and FA diets exhibited antihypertensive effects through reducing $\mathrm{BP}$ and $\mathrm{ACE}$ activity. Although both diets had the effect of lowering the plasma albumin levels, only the DF diet reduced the levels of BUN and the BUN:creatinine ratio.

Oxidative stress plays an important role in the initiation and progression of CVD, including hypertension, type II diabetes and hypercholesterolaemia (Hamilton et al. 2004). In the present study, the $\mathrm{C}$ diet group showed the development of a higher BP and plasma NOx level compared to the DF and FA diet groups. Moreover, only the urinary NOx level was reduced in the DF diet group. The same phenomenon has been shown in SHRSP following dietary black and green tea polyphenol feeding for 3 weeks (Negishi et al. 2004). Systolic and diastolic BP levels were significantly lower in the black and green tea polyphenol-fed group, and plasma and urinary NO levels were also lower in this group (Negishi et al. 2004). In addition, potent antioxidant therapy for ameliorating hypertension lowered urinary NOx metabolite excretion (Vaziri et al. 2000). It has been suggested that the DF, containing not only FA but also other phenolics as bioactive compounds, contributes to a decrease in the NOx levels in the plasma and urine. Our previous study showed that the DF contained phenolic compounds $(64.74 \mathrm{mg} / \mathrm{g}$ gallic acid equivalent) including FA $(0 \cdot 19 \mathrm{mg} / 100 \mathrm{~g} \mathrm{DF})$ (Ardiansyah et al. 2006). Another study demonstrated that bioactive components such as the flavonoid derivatives morusin, kuwanon $\mathrm{C}$ and sanggenon $\mathrm{D}$, and biflavonoids such as bilobetin and ginkgetin decreased the availability of basal NO (Kim et al. 1999; Cheon et al. 2000; Raso et al. 2001). The present results showed that the urinary $8-\mathrm{OHdG}$ level of the DF and FA diet groups were significantly decreased compared with the $\mathrm{C}$ diet group after 8 weeks of administration. Urinary 8 -OHdG has been reported to serve as a sensitive biomarker of oxidative stress and resulting genetic damage. In another study (Ling et al. 2002), dietary supplementation with the outer layer of black rice significantly lowered the aortic 8-OHdG level compared with the administration of a highcholesterol diet, and its level with the supplemented diet was the same as that of the normal diet. The present data indicate that the supplementation of a diet with the DF from rice bran and FA reduces the oxidative stress. Since oxidative stress plays an important role in the development of CVD, the decreased DNA oxidative damage due to the DF derived from rice bran and FA supplementation could contribute towards inhibiting the progression of hypertension in SHRSP via decreased DNA oxidative damage.

The PEPCK and G6Pase genes encode rate-controlling enzymes of hepatic gluconeogenesis. The physiological significance of the dysregulation of hepatic gluconeogenic genes is supported by the observation of the overexpression of both PEPCK and G6Pase in the liver; several groups have studied the metabolic and physiological consequences of altering either PEPCK or G6Pase in vivo (Arion et al. 1980; Valera et al. 1994; Sun et al. 2002). The results of the present study showed that the DF and FA diets contributed to a reduction in the fasting plasma and incremental area under the curve glucose levels. On the other hand, the FA diet showed a significant up-regulation in mRNA levels of the PEPCK gene involved in plasma insulin metabolism; none of the experimental diets had any effect on the expression of the G6Pase gene. Another study showed that amide compounds from FA such as $n$-butyl, n-pentyl, pyrrolidine and piperidine strongly stimulated insulin secretion from the RIN-5F cells compared to cells in a control group (Nomura et al. 2003). From this viewpoint, the present study suggests that the FA diet induced hyperinsulinaemic conditions in the SHRSP, even though the administration of FA was shown to improve several diabetic parameters in other experimental systems.

Diets supplemented with rice bran (crude or parboiled) reduced the plasma LDL-C and liver cholesterol contents in Sprague-Dawley rats that were fed a high cholesterol diet for 3 weeks (Rouanet et al. 1993). On the other hand, it has been reported that there are no differences in the serum lipids of rabbits among groups fed high cholesterol, white rice fraction and black rice fraction (Mattews et al. 1985). Another study also reported that supplementation of rice bran was similar to white rice and brown rice in the plasma and liver lipid concentration (Marsono et al. 1993). Our previous study demonstrated that the DF from rice bran reduces plasma lipid parameters and its effect is greater than that of an ethanol fraction (Ardiansyah et al. 2006). The present results indicate that there was a significant decrease in plasma TC, LDL-C and TG levels in the DF and FA diet groups compared with the $\mathrm{C}$ diet group. Moreover, there was a significant decrease in the total lipid and TG levels of the liver of the DF diet group. On the other hand, the FA diet group showed an increase in the total lipid content but 
no significant difference in the $\mathrm{TG}$ content compared to the $\mathrm{C}$ group. The FA diet group exhibited increased insulin level; this condition increases lipolysis and releases more NEFA into the blood (Agardh et al. 1999). Enhanced lipolysis during diabetes also increases the synthesis of phospholipid; therefore, these conditions enhanced the level of hepatic total lipid in the FA diet group. Nevertheless, the exact mechanism by which FA lowers the plasma lipid levels is not known. Some studies report that FA significantly lowers the plasma TC and TG levels in Wistar rats after induction with streptozotocin (Balasubashini et al. 2003). Another study also reports that FA does not significantly decrease lipid parameters in Sprague-Dawley rats (Frank et al. 2003). This discrepancy could be due to the different animal models used. Future study is needed to explain these mediators to clarify the mechanism underlying the present experimental result despite the fact that FA has a potent antioxidant activity in vitro (Conessa et al. 1999; Saija et al. 1999). From this viewpoint, the present study suggests that the DF from rice bran exerted a hypolipidaemic effect and this is considerably more effective than FA as a purified component. Therefore, we presume that the DF might play a protective role against the hyperlipidaemic effect in hypertensive conditions.

The mechanism that underlies the hypocholesterolaemic action of the DF diet group remains unknown. There are two possible mechanisms that might explain the decrease in the values of lipid parameters after the administration of the rice bran diet. First, rice bran enhances the binding capacity of the LDL receptor to LDL and that concomitantly, HDL binding activity tends to be inversely related to LDL receptor activity. Topping et al. (1990) report that the binding capacity of LDL by the LDL receptor is higher in Wistar rats fed rice bran than in animals fed wheat bran. Second, the enzymatic activity of hepatic cholesterol-7 $\alpha$-hydroxylase (Cyp7a1), the rate-limiting enzyme in bile acids biosynthesis, is elevated and contributes to stimulate cholesterol conversion to bile acids, resulting in the elimination of cholesterol from the body. Illman \& Topping (1985) and Topping et al. (1990) found that feeding oat bran and rice bran diets to Wistar rats triggered off an increase in faecal bile acid and sterol excretion; this explains the low level of plasma LDL-C in animals fed dietary rice bran by means of a compensatory mechanism entailing the uptake of LDL-C by the liver.

Cholesterol homeostasis is facilitated in the liver through a complex series of pathways involving the uptake of plasma cholesterol, the synthesis of cholesterol from acetate, the direct transport of free cholesterol to the bile and the elimination of cholesterol via synthesis of bile acid (Chiang, 2002). Qureshi et al. (2002) have shown that tocotrienol, one of the major compounds present in rice bran, is effective in lowering the serum TC and LDL-C levels and acts by inhibiting the activity of the hepatic enzyme 3-hydroxy-3-methylglutaryl-CoA reductase through a post-transcriptional mechanism. The present study revealed that there was a significant increase in the mRNA levels of 3-hydroxy-3-methylglutaryl-CoA reductase in the FA diet group; however, there was no difference in the DF diet group compared to the $\mathrm{C}$ diet group. FXR, a bile acid receptor that regulates the transcription of numerous genes, is involved in maintaining cholesterol and bile acid homeostasis (Makishima et al. 1999; Wang et al. 1999). The present study showed that, compared to the C diet, FXR mRNA levels were significantly promoted by the FA diet and repressed by the DF diet. The expression levels of the SHP and MRP2 target genes of the FXR also showed the same results. We supposed that up-regulation of the mRNA expression level of FXR, SHP and MRP2 seems paralleled to the increased hepatic TG of the FA diet group, but not in the DF diet group.

The DF and FA diet groups also showed a significant downregulation in the mRNA levels of very long-chain acyl-CoA synthetase, one of the genes involved in TG metabolism. Ikemoto et al. (1997) reported hepatic TG levels parallel to ACS mRNA expression level, although the present results showed that only hepatic TG significantly decreased with the DF diet. Moreover, the expression levels of liver fatty acid-binding protein, which plays a potential role in fatty acid storage and $\beta$-oxidation processes, showed significant down-regulation with the DF diet. Both of the genes (very long-chain acyl-CoA synthetase and liver fatty acid-binding protein) related to the decreased level of TG in the liver. The present observations suggest that the lipid metabolism in SHRSP may be regulated by different mechanisms in those animals fed DF and FA as supplementary diets. Future studies are required to analyse the detailed mechanisms.

In summary, we describe that supplementation of diets with the DF of rice bran produces numerous protective effects against hypertension, hyperglycaemia and hyperlipidaemia, and that these effects are more pronounced than those of an FA-supplemented diet. Moreover, the DF of rice bran is an excellent functional food derived from cereal and can be used for the purpose of dietary manipulation and has potential clinical implications as a naturally occurring dietary supplement in the absence of therapeutic agents. Future studies will be required to analyse in detail the antihypertensive, antihyperglycaemic and antihyperlipidaemic properties inherent in the DF of rice bran.

\section{Acknowledgements}

This study was supported in part by The Iijima Memorial Foundation for the Promotion of Food Science and Technology. The authors gratefully acknowledge the technical assistance, discussion and helpful suggestions of Nur Hayati, Yumi Sugita and Takuya Hashimoto.

\section{References}

Abdel-Aal ESM, Huci P, Sosulski FW, Graf R, Gillott C \& Pietrzak L (2001) Screening spring wheat for midge resistance in relation to ferulic acid content. J Agric Food Chem 49, 3559-3566.

Agardh CD, Bjorgell P \& Nilsson EP (1999) The effects of tolbutamide on lipoproteins, lipoprotein lipase and hormone-sensitive lipase. Diabetes Res Clin Pract 46, 99-108.

Aitman TJ, Gotoda T, Evans AL, et al. (1997) Quantitative trait loci for cellular defects in glucose and fatty acid metabolism in hypertensive rats. Nat Genet 16, 197-201.

Ardiansyah, Shirakawa H, Koseki T, Ohinata K, Hashizume K \& Komai M (2006) Rice bran fractions improve blood pressure, lipid profile, and glucose metabolism in stroke-prone spontaneously hypertensive rats. J Agric Food Chem 54, 1914-1920.

Arion WJ, Lange AJ, Walls HE \& Ballas LM (1980) Evidence for the participation of independent translocation for phosphate and 
glucose 6-phosphate in the microsomal glucose-6-phosphatase system. Interactions of the system with orthophosphate, inorganic pyrophosphate, and carbamyl phosphate. J Biol Chem $\mathbf{2 5 5}$, 10396-10406.

Astawan M, Wahyuni M, Yasuhara T, Yamada K, Tadokoro T \& Maekawa A (1995) Effect of angiotensin I-converting enzyme inhibitory substances derived from Indonesian dried-salted fish on blood pressure of rats. Biosci Biotech Biochem 59, 425-429.

Balasubashini MS, Rukkumani R \& Menon VP (2003) Protective effects of ferulic acid on hyperlipidemic diabetic rats. Acta Diabetol 40, 118-122.

Cheon BS, Kim YH, Son KS, Chang HW, Kang SS \& Kim HP (2000) Effects of prenylated flavonoids and bioavailability on lipopolysaccharide-induced nitric oxide production from the mouse macrophage cell line RAW 264.7. Planta Med 66, 596-600.

Chiang JY (2002) Bile acid regulation of gene expression: roles of nuclear hormone receptors. Endocr Rev 23, 443-463.

Choi SW, Nam SH \& Choi HC (1996) Antioxidative activity of ethanolic extracts of rice brans. Foods Biotechnol 5, 305-309.

Collison M, Glazier AM, Graham D, Morton JJ, Dominiczak MH, Aitman TJ, Connell JM, Gould GW \& Dominiczak AF (2000) $\mathrm{Cd} 36$ and molecular mechanisms of insulin resistance in the stroke-prone spontaneously hypertensive rat. Diabetes $\mathbf{4 9}$, 2222-2226.

Conessa MTG, Wilson PD, Plumb GW, Ralp J \& Williamson G (1999) Antioxidant properties of 4,4'-dihydroxy-3,3'-dimethoxy$\beta, \beta^{\prime}$-bicinnamic acid (8-8-diferulic acid, non-cyclic form). $J$ Sci Food Agric 79, 279-284.

Cushman DW \& Cheung HS (1971) Spectrophotometric assay and properties of the angiotension-converting enzyme of rabbit lung. Biochem Pharmacol 20, 1637-1648.

FitzGerald RJ, Murray BA \& Walsh DJ (2004) Hypotensive peptides from milk proteins. J Nutr 134, 980S-988S.

Folch J, Lees M \& Stanley GHS (1957) A simple method for the isolation and purification of total lipid from animal tissues. $J$ Biol Chem 226, 497-509.

Frank J, Kamal-Eldin A, Razdan A, Lundh T \& Vessby B (2003) The dietary hydroxycinnamate caffeic acid and its conjugate chlorogenic acid increase vitamin $\mathrm{E}$ and cholesterol concentration in Sprague-Dawley rats. J Agric Food Chem 51, 2526-2531.

Friedewald WT, Levy RI \& Fredrickson DS (1972) Estimation of the concentration of low-density lipoprotein cholesterol in plasma without use of the preparative ultracentrifuge. Clin Chem 18, 499-502.

Groener JEM, Gent Tv \& Tol Av (1989) Effect of lipid transfer protein on plasma lipids, apoliproteins and metabolism of highdensity lipoprotein cholesteryl ester in the rat. Biochim Biophys Acta 1002, 93-100.

Hamilton CA, Miller WH, Al-benna S, Brosnan MJ, Drummond RD, McBridge MW \& Dominiczak AF (2004) Strategies to reduce oxidative stress in cardiovascular disease. Clin Sci 106, 219-234.

Hu C, Zawistowski J, Ling W \& Kitts DD (2003) Black rice (Oryza sativa L. indica) pigmented fraction suppresses both reactive oxygen species and nitric oxide in chemical and biological model systems. J Agric Food Chem 51, 5271-5277.

Ikemoto S, Takahashi M, Tsunoda N, et al. (1997) Cholate inhibits high-fat diet-induced hyperglycemia and obesity with acyl-CoA synthetase mRNA decrease. Am J Physiol 273, E37-E45.

Illman RJ \& Topping DL (1985) Effect of dietary oat bran on fecal steroid excretion, plasma volatile fatty acids and lipid synthesis in rat. Nutr Res 5, 839-846.

Kim HK, Cheon BS, Kim YH, Kim SY \& Kim HP (1999) Effect of naturally occurring flavonoids on nitric oxide production in the macrophage cell line RAW 264.7 and their structure activity relationships. Biochem Pharmacol 58, 759-765.

Lee MC, Shouji H, Miyazaki H, Yoshino F, Hori N, Toyoda M, Ikeda Y, Anzai K, Ikota N \& Ozawa T (2004) Assessment of oxidative stress in the spontaneously hypertensive rat brain using electron spin resonance (ESR) imaging and in vivo L-band ESR. Hypertens Res 27, 485-492.

Ling WH, Wang LL \& Ma J (2002) Supplementation of the black rice outer layer fraction to rabbits decreases atherosclerotic plaque formation and increases antioxidant status. J Nutr 132, $20-26$.

Makishima M, Okamoto AY, Repa JJ, Tu H, Learned RM, Luk A, Hull MV, Lustig KD, Mangelsdorf DJ \& Shan B (1999) Identification of a nuclear receptor for bile acids. Science 284, $1362-1365$.

Marsono Y, Illman RJ, Clarke JM, Trimble RP \& Topping DL (1993) Plasma lipids and large bowel volatile fatty acids in pigs fed on white rice and rice bran. Br J Nutr 70, 503-513.

Mattews DR, Hosker JP, Rudenski AS, Naylor BA, Treacher DF \& Turner RC (1985) Homeostasis model assessment: insulin resistance and beta-cell function from fasting plasma glucose and insulin concentrations in man. Diabetologia 28, 412-419.

Negishi H, Xu JW, Ikeda K, Njelekela M, Nara Y \& Yamori Y (2004) Black and green tea polyphenols attenuate blood pressure increases in stroke-prone spontaneously hypertensive rats. J Nutr 134, $38-42$.

Nomura E, Kashiwada A, Hosoda A, Nakamura K, Morishita H, Tsuno T \& Taniguchi H (2003) Synthesis of amide compounds of ferulic acid, and their stimulatory effects on insulin secretion in vitro. Bioorg Med Chem 11, 3807-3813.

Okamoto K, Yamori Y \& Nagaoka A (1974) Establishment of the stroke-prone spontaneously hypertensive rat (SHR). Circ Res 34/ 35, $143-153$

Qureshi AA, Mo H, Packer L \& Peterson DM (2000) Isolation and identification of novel tocotrienol from rice bran with hypocholesterolemic, antioxidant, and antitumor properties. J Agric Food Chem 48, 3130-3140.

Qureshi AA, Sami SA, Salser WA \& Khan FA (2002) Dose-dependent suppression of serum cholesterol by tocotrienol-rich fraction (TRF25) of rice bran in hypercholesterolamic human. Atherosclerosis 161, 199-207.

Raso GM, Meli R, Di-Carlo G, Pacilio M \& Di-Carlo R (2001) Inhibition of inducible nitric oxide synthase and cyclooxygenase-2 expression by flavonoid in macrophage J774A 1 . Life Sci 68, 921-931.

Reeves PG, Nielsen FH \& Fahey GC (1993) AIN-93 purified diets for laboratory rodents: final report of the American Institute of Nutrition ad hoc writing committee on reformulation of the AIN-76A rodent diet. J Nutr 123, 1939-1951.

Rouanet JM, Laurent C \& Besacon P (1993) Rice bran and wheat bran: selective effect on plasma and liver cholesterol in highcholesterol fed rats. Food Chem 47, 67-71.

Saija A, Tomaino A, Cascio RL, Trombetta D, Proteggente A, Pasquale AD, Uccella N \& Bonina F (1999) Ferulic and caffeic acids as potential protective agents against photooxidative skin damage. J Sci Food Agric 79, 476-480.

Sato M, Hosokawa T, Yamaguchi T, Nakano T, Muramoto K, Kahara T, Funayama K, Kobayashi A \& Nakano T (2002) Angiotensin Iconverting enzyme inhibitory peptides derived from Wakame (Undaria pinnatifida) and their antihypertensive effect in spontaneously hypertensive rats. $J$ Agric Food Chem 50, $6245-6252$.

Saunders RM (1990) The properties of rice bran as a food stuff. Cer Foods Worlds 35, 632-636.

Sharifi AM, Darabi R \& Akbarloo N (2003) Investigation of antihypertensive mechanism of garlic in $2 \mathrm{~K} 1 \mathrm{C}$ hypertensive rat. $J$ Ethnopharmacol 86, 219-224.

Sheetharamaiah GS \& Chadrasekhara N (1988) Hypocholesterolemic activity of aryzanol in rats. Nutr Rep Int 38, 927-935.

Shimizu E, Hayashi A, Takahashi R, Aoyagi Y, Murakami T \& Kimoto K (1999) Effect of angiotensin I-converting enzyme inhibitor from Ashitaba (Angelica keiskei) on blood pressure of 
spontaneously hypertensive rats. J Nutr Sci Vitaminol 45, $375-383$.

Smith MM \& Hartley RD (1983) Occurrence and nature of ferulic acid substitution of cell wall polysaccharides in gramineous plants. Carbohydr Res 118, 65-80.

Sun Y, Liu S, Ferguson S, Wang LQ, Klepcyk P, Yun JS \& Friedman JE (2002) Phosphoenolpyruvate carboxykinase overexpression selectively attenuates insulin signaling and hepatic insulin sensitivity in transgenic mice. $J$ Biol Chem 277, 23301-23307.

Suzuki A, Kagawa D, Fujii A, Ochiai R, Tokimitsu I \& Saito I (2002) Short and long term effect of ferulic acid on blood pressure in spontaneously hypertensive rats. Am J Hypertens 15, $351-357$.

Topping DL, Illman RJ, Roach PD, Trible RD, Kambouris A \& Nestel PJ (1990) Modulation of the hypolipidemic effect of fish oils by dietary fiber in rats. $J$ Nutr 120, 325-330.

Toyokuni S, Itani T, Morimitsu Y, Okada K, Ozeki M, Kondo S, Uchida K, Osawa T, Hiai H \& Tashiro T (2002) Protective effect of colored rice over white rice on Fenton reaction-based renal lipid peroxidation in rats. Free Radic Res 36, 583-592.

Valera A, Pujol A, Pelegrin M \& Bosch F (1994) Transgenic mice overexpressing phosphoenolpyruvate carboxykinase develop noninsulin-dependent diabetes mellitus. Proc Natl Acad Sci U S A 91, 9151-9154.
Vaziri N, Ni Z, Oveisi F \& Trnavsky-Hobbs D (2000) Effect of antioxidant therapy on blood pressure and NO synthase expression in hypertensive rats. Hypertension 36, 957-964.

Wang H, Chen J, Hollister K, Sowers LC \& Forman BM (1999) Endogenous bile acids are ligands for the nuclear receptor FXR/ BAR. Mol Cell 3, 543-553.

Wolever TMS \& Jenkins DJA (1986) The use the glycemic index in predicting the blood glucose response to mixed meals. Am J Clin Nutr 43, 167-172.

Wu J \& Ding X (2001) Hypotensive and physiological effect of angiotensin converting enzyme inhibitory peptides derived from soy protein on spontaneously hypertensive rats. J Agric Food Chem 49, 501-509.

Yamori Y, Mori C, Nishio T, et al. (1979) Cardiac hypertrophy in early hypertension. Am J Cardiol 44, 964-969.

Yan JJ, Cho JY, Kim HS, Kim KL, Jung JS, Huh SO, Suh HW, Kim YH \& Song DK (2001) Protection against beta-amyloid peptide toxicity in vivo with long term administration of ferulic acid. Br J Pharmacol 133, 89-96.

Yang HY, Yang SC, Chen JR, Tzeng YH \& Han BC (2004) Soyabean protein hydrolysate prevents the development of hypertension in spontaneously hypertensive rats. Br J Nutr 92, 507-512.

Yang Y, Marczak ED, Yokoo M, Usui H \& Yoshikawa M (2003) Isolation and antihypertensive effect of angiotensin I-converting enzyme (ACE) inhibitory peptide from spinach Rubisco. J Agric Food Chem 51, 4897-4902. 